\title{
Flame Temperatures Saturate with Increasing Dead Material in Ulex europaeus, but Flame Duration, Fuel Consumption and Overall Flammability Continue to Increase
}

\author{
Jennifer M. Dent ${ }^{1}$, , Hannah L. Buckley ${ }^{1,2}$, Audrey Lustig ${ }^{3,4}$ and Timothy J. Curran ${ }^{1, *(1)}$ \\ 1 Department of Pest-management and Conservation, PO Box 85084, Lincoln University, \\ Canterbury 7647, New Zealand; jenny.dent@lincolnuni.ac.nz (J.M.D.); hannah.buckley@aut.ac.nz (H.L.B.) \\ 2 School of Science, Auckland University of Technology, Auckland 1010, New Zealand \\ 3 Bio-Protection Research Centre, PO Box 85084, Lincoln University, Canterbury 7647, New Zealand; \\ audrey.lustig@gmail.com \\ 4 Geospatial Research Institute, University of Canterbury, Private Bag 4800, Christchurch 8140, New Zealand \\ * Correspondence: Timothy.Curran@lincoln.ac.nz
}

Received: 6 December 2018; Accepted: 24 January 2019; Published: 29 January 2019

check for updates

\begin{abstract}
A key determinant of wildfire behaviour is the flammability of constituent plants. One plant trait that influences flammability is the retention of dead biomass, as the low moisture content of dead material means less energy is required to achieve combustion. However, the effect of the dead-to-live ratio of fuel on plant flammability has rarely been experimentally quantified. Here we examine the nature of the relationship between dead fuel accumulation and flammability in Ulex europaeus (common gorse). Shoots with varying proportions of dead material were ignited in a purpose-built plant-burner. Three components of flammability were measured: sustainability (flame duration), consumability (proportion burnt biomass) and combustibility (maximum temperature). While flame duration and proportion burnt biomass had a positive linear relationship with the proportion of dead material, the response of maximum temperature was positive but non-linear. All three flammability components were reduced to a single variable using principal components analysis; this had a non-linear relationship with the proportion of dead material. The response of maximum temperature to dead material plateaued at 39\%. These findings have implications for the management of habitats invaded by gorse; to mitigate fire hazard associated with gorse, stands should be kept at a relatively young age when dead fuel is less prevalent.
\end{abstract}

Keywords: gorse; sustainability; combustibility; consumability; flammability threshold; New Zealand

\section{Introduction}

A key determinant of fire behaviour is the flammability of constituent plants [1,2]. Plant flammability has four components; ignitability, combustibility, consumability and sustainability [3,4]. Ignitability is how easily a plant ignites once exposed to a heat source, combustibility is how rapidly or intensely a plant burns, sustainability is the length of time that a plant can sustain fire, and finally, consumability is how completely the plant burns [3,4]. The presence of highly flammable plants within communities can dramatically change fire regimes, for instance by increasing fire intensity and the rate of spread [5].

One of the most important plant traits driving flammability is the production and/or retention of dead material [1,6]. Dead material is typically more flammable than living tissue due to the associated reduction in moisture content [1]. Lower water content means that less energy is necessary to achieve 
combustion [7]. Some species, including Ulex spp. (gorse) exploit this relationship, achieving elevated flammability via accumulation of dead material [8-10]. Each growing season, material from the previous growing season tends to die off naturally, establishing a core of highly flammable dead material [11].

As a consequence, communities that are dominated by Ulex spp. are considered to be some of the most fire-prone types of shrubland [9,12]. The retention of dead material is considered an adaptive strategy in gorse as, in addition to removing competitors, fire promotes germination from the seed bank, which allows for rapid post-fire regeneration [11,13]. Established gorse plants can also rapidly resprout from burnt stumps with up to $46 \%$ of plants resprouting in some populations [14].

Although the retention of dead biomass in gorse is frequently cited as a flammability-enhancing trait $[9,11,12]$, the effect of the dead-to-live ratio on plant flammability and fire behaviour has yet to be experimentally quantified [15]. The aim of this study was to quantify the nature of the relationship between the proportion of dead material and flammability in Ulex europaeus (common gorse). Specifically, does flammability increase linearly with increased dead material, or does it saturate after reaching a certain threshold of dead material, as noted for some species [8]? The ability to anticipate trait-driven flammability responses will facilitate more effective management of gorse-dominated vegetation.

\section{Method}

\subsection{Study Species}

Ulex europaeus (L.) (common gorse) is a woody leguminous species originating from Europe that has become an invasive weed in many countries, including New Zealand [11]. In areas where it is invasive, U. europaeus often grows in large, dense stands [16]. Ulex spp. are considered to be highly flammable due to the accumulation of dead biomass [11].

\subsection{Sample Collection}

Samples of $U$. europaeus used in this study were collected near Tai Tapu, Canterbury, New Zealand, where U. europaeus dominates the hillside and forms dense thickets ( $\left.43^{\circ} 38^{\prime} 43^{\prime \prime} \mathrm{S}, 172^{\circ} 35^{\prime} 13^{\prime \prime} \mathrm{E}\right)$. Shoots of $70 \mathrm{~cm}$ length were taken from mature individuals at this site in November 2012. An assortment of both live and dead material was taken during two collection events. Though it was not raining during either collection, rain had fallen in the evening prior to the first collection.

\subsection{Experimental Procedure}

Immediately after sampling, the water content of each sample was assessed. A small sub-sample (5-10 cm length shoot) was taken from each sample of $U$. europaeus and weighed to establish fresh weight. The sub-sample was then oven dried for $48 \mathrm{hrs}$ at $65^{\circ} \mathrm{C}$. The change in weight of the subsample following drying was used to measure water content (\%) on a fresh weight basis.

Flammability analysis occurred on the same day as collection. The proportion of dead material on each sample was estimated visually. In some trials the amount of dead material was manipulated by combining subsets of different samples. This allowed a wider range of dead-to-live ratios to be assessed (0-100\% dead material).

The burning itself was conducted using a device designed by Jaureguiberry et al. [17] and modified to meet New Zealand Safety Standards [18]. The device consisted of an $85 \mathrm{~cm} \times 60 \mathrm{~cm}$ half-cut metal barrel which was fitted with a single burner, a grill and a blow torch. The burner and blowtorch were connected to a propane-butane gas cylinder (Figure 1). Further details of the device are provided by Wyse et al. [18,19].

The $U$. europaeus samples were placed horizontally on the surface of the grill; they were orientated so that the base of the sample lined up with the blowtorch, as this was believed to be the best representation of natural ignition. In mixed-sample trials, the dead material portion was positioned 
underneath the live material portion to reflect natural conditions (Figure 2). In instances where no single sample contained a desired proportion of dead material, the latter variable was manipulated by removing parts of the sample or by adding amounts of other material to the existing sample.

Flammability measurements were made following Wyse et al. [18] whereby each plant sample was preheated for $120 \mathrm{~s}$ using the burners. The blowtorch was then switched on for $10 \mathrm{~s}$ to provide an ignition source. Once the blow torch had been switched off, the combustibility, sustainability and consumability of the sample were determined. Combustibility was assessed in terms of maximum temperature reached $\left({ }^{\circ} \mathrm{C}\right)$; this was recorded using an infrared thermometer (Fluke 572; Fluke Corp., Everett, WA, USA) $[17,18]$. Sustainability was quantified as flame duration (seconds). This was defined as the length of time, after the blowtorch had been turned off, that the sample supported a flaming combustion. Finally, consumability was assessed visually by estimating the proportion of available biomass which was burnt (\%) [18,20]. Percentage burnt biomass was estimated to the nearest 5\% or other $\%$ where appropriate (e.g. $2 \%$ if smaller gradations were warranted). A total of 31 burns were conducted in this manner over two days. Weather data were recorded on both days using a Kestrel 4000 weather logger (Loftopia; Birmingham, MI, USA), temperatures ranged from a mean of $12.1^{\circ} \mathrm{C}$ (Day 1 ) to $13.2{ }^{\circ} \mathrm{C}$ (Day 2) while mean humidity was $50.1 \%$ and $40.6 \%$ respectively. To test whether these weather differences affected our flammability readings, we ran a GLM and found no significant day effect $(P>0.05)$ for any of our variables.

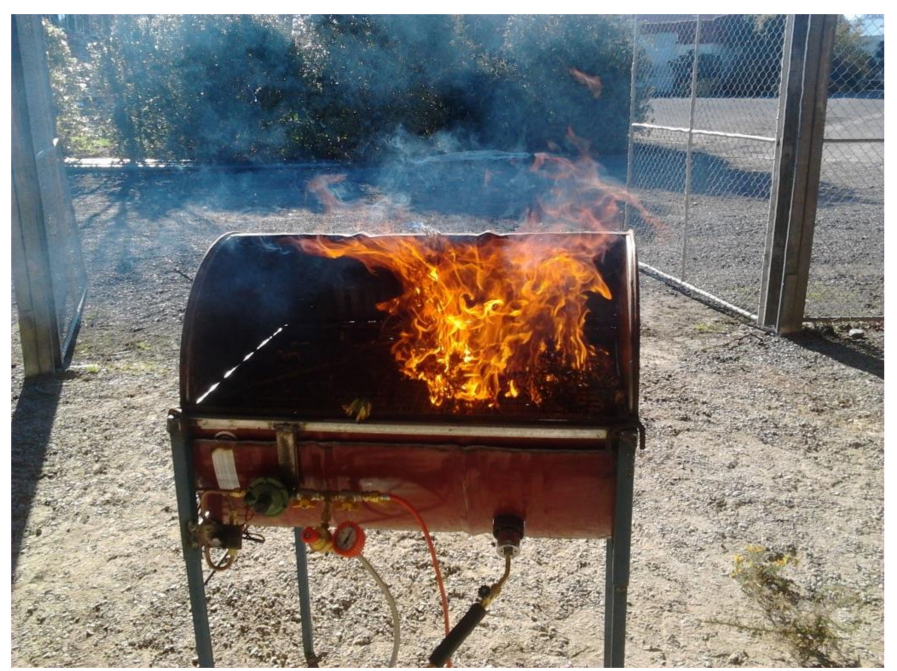

Figure 1. The device used for flammability measurements (Photo: T Curran).

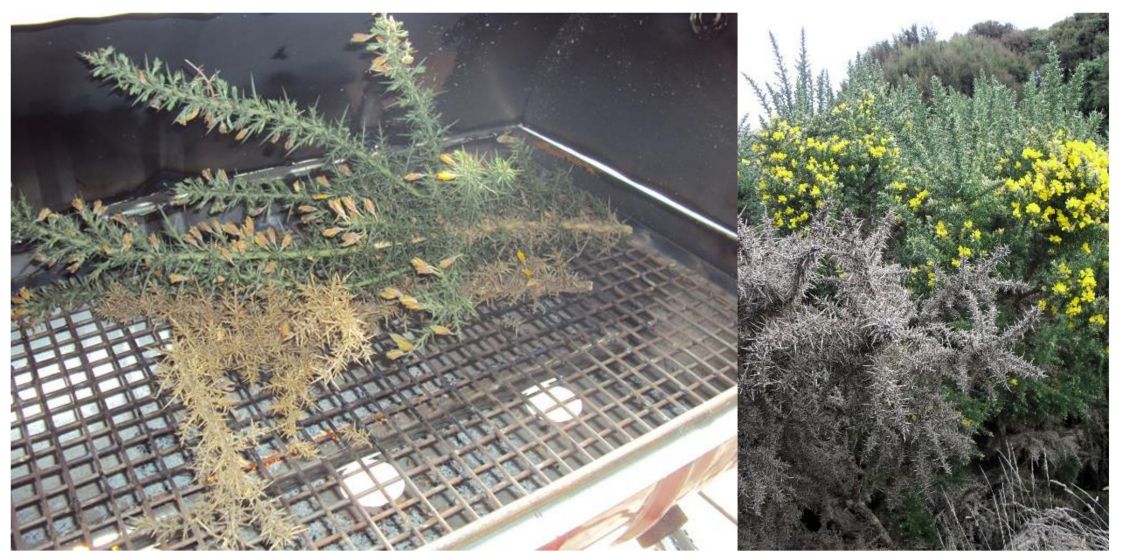

Figure 2. Showing placement of multiple samples on the grill (left), with dead material placed below the live material to be closer to the ignition source, and gorse in situ on Banks Peninsula, showing the dead material held underneath the live material, and the presence of horizontal shoots. (Photos J Dent and T Curran). 


\subsection{Data Analysis}

The three individual measures of flammability were reduced into a single variable using principal component analysis (PCA), as per $[18,19,21]$. This provided a means of examining overall flammability.

Before data from the two collection events were pooled, one-way analysis of variance was used to test for differences in moisture content of samples collected on different days. Another one-way analysis of variance was used to test the assumption that dead material has lower water content. In this case, Welch's correction was applied to account for the heteroscedasticity derived from unequal group size [22].

Non-linear regression was used to examine the relationship between flammability (combustibility, consumability, sustainability, overall flammability) and the proportion of dead material. In the case of combustibility and overall flammability, multiple models appeared to describe the data well. The small sample size corrected form of Akaike's information criterion (AICc) was employed to assess the relative quality of each candidate model [23]. For both maximum temperature and overall flammability there was most support for the polynomial and asymptotic models (Tables 1 and 2). We considered that the asymptotic model was the best one to proceed with as we could think of no sound biological reason as to why flammability would decrease at the highest proportions of dead material. Piecewise regression was then used to estimate the model breakpoint which was interpreted as the flammability threshold [24]. Pearson's correlation coefficient values were also calculated among the different aspects of flammability. Data analyses were performed using $\mathrm{R}$ version 2.14 (R Development Core Team 2011).

Table 1. Model selection for maximum temperature (combustibility) analysis.

\begin{tabular}{cccc}
\hline Model & K & AICc & Delta AICc \\
\hline Polynomial & 4 & 392.6 & 0.00 \\
Asymptotic & 4 & 393.1 & 0.54 \\
Linear & 3 & 400.9 & 8.36 \\
\hline
\end{tabular}

Table 2. Model selection for overall flammability (PCA 1) analysis.

\begin{tabular}{cccc}
\hline Model & K & AICc & Delta AICc \\
\hline Polynomial & 4 & 70.47 & 0.00 \\
Asymptotic & 4 & 70.76 & 0.29 \\
Linear & 3 & 76.02 & 5.55 \\
\hline
\end{tabular}

\section{Results}

Live material was confirmed to have a significantly higher moisture content than dead material (59.7\% SE \pm 1.6 and $16.5 \% \mathrm{SE} \pm 1.10$ respectively, $\left.F_{1,40}=453.4, P<0.0001\right)$. There was no significant difference in water content between collection events $\left(F_{1,29}=1.1, P=0.3\right)$ and so data from both days were pooled for further analysis. The correlation matrix indicated that all three measures of flammability in this study were strongly and positively correlated (Pearson's $r$ values ranged from 0.80 to 0.87 ).

Principal component analysis generated three principal components. The first principal component was the most important of the analysis as it explained $88.69 \%$ of the total variance (s.d. $=1.63$ ), it was therefore selected for modelling purposes. Factor loading within the first principal component was relatively uniform; maximum temperature had the greatest factor loading (0.585), while proportion of burnt biomass and flame duration had slightly lower loading values ( 0.579 and 0.568 , respectively).

There was a positive linear relationship between proportion of burnt biomass and the proportion of dead material; $Y=1.23 X+0.24(Y=$ proportion of burnt biomass, $X=$ proportion of dead material; $R^{2}=0.92, F_{1,29}=370.4, P<0.0001 ;$ Figure 3$)$. There was also a positive linear relationship between flame duration and the proportion of dead material; $Y=61.24 X+11.21$ ( $Y=$ flame duration, $X=$ proportion of dead material; $R^{2}=0.58, F_{1,29}=42.39, P<0.0001$; Figure 3). AICc comparison of 
the non-linear models indicated that a non-linear, asymptotic model was an appropriate model for assessing maximum temperature; $Y=721.73-603.69 \times 0.038^{X}(Y=$ maximum temperature, $\mathrm{X}=$ proportion of dead material, Figure 3). The piecewise regression breakpoint for this relationship was $\mathrm{X}=0.386$ ( $\mathrm{SE} \pm 0.093, P=0.01$ ); this corresponds to a dead material threshold of $39 \%$ (Figure 4 ). The asymptotic model for overall flammability (PCA Axis 1 score) yielded the following relationship; $Y=2.72-5.45 \times 0.166^{\mathrm{X}}(\mathrm{Y}=$ overall flammability, $\mathrm{X}=$ proportion of dead material, Figure 3$)$. The piecewise regression breakpoint for this relationship was $X=0.392$ ( $\mathrm{SE} \pm 0.11, P<0.03$ ); this also corresponded to a dead material threshold of $39 \%$ (Figure 4). The change in slope at the breakpoint was less steep in the overall flammability model (63\% decrease) than the maximum temperature model (85\% decrease; Figure 4).
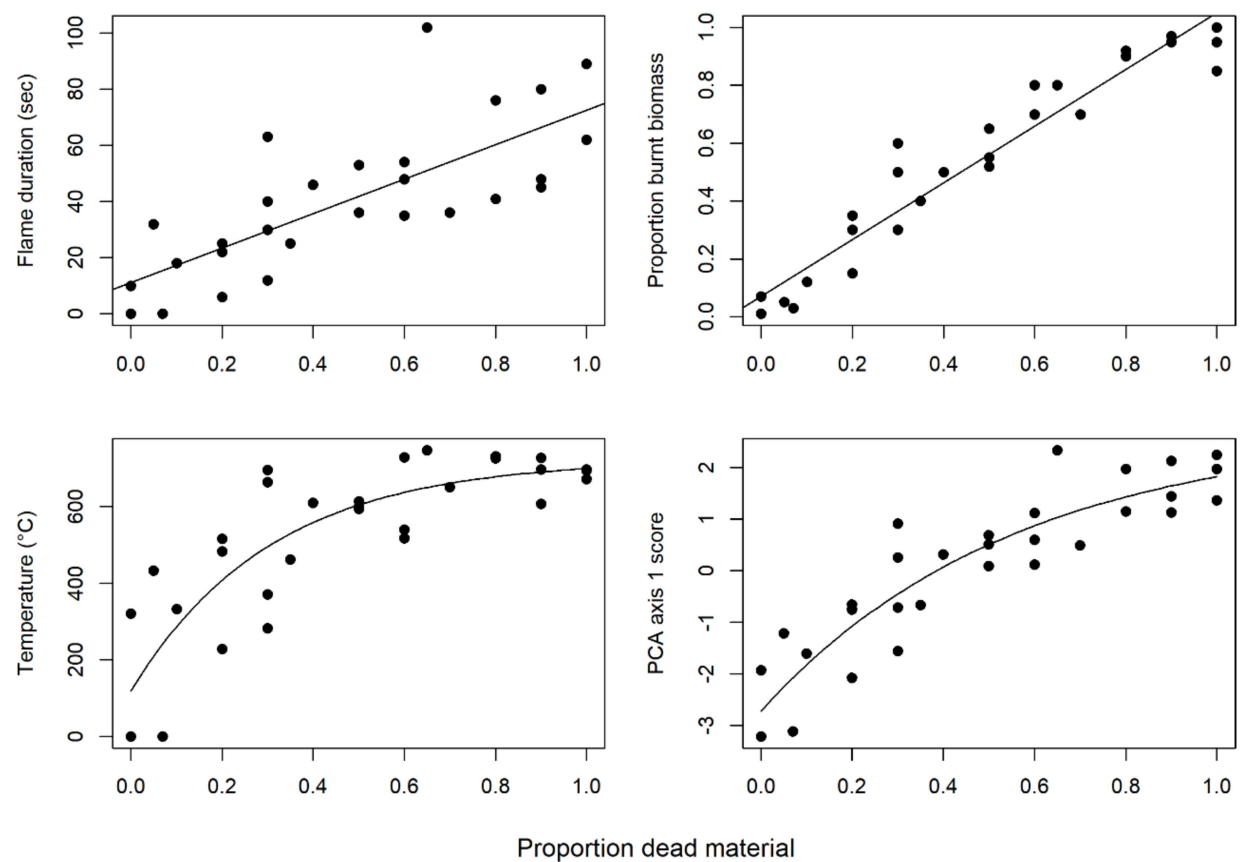

Figure 3. The relationship between the proportion of dead material in the burnt sample and the sustainability (flame duration (seconds)), consumability (burnt biomass), combustibility (temperature $\left({ }^{\circ} \mathrm{C}\right)$ and overall flammability (PCA axis 1 scores) of the sample.

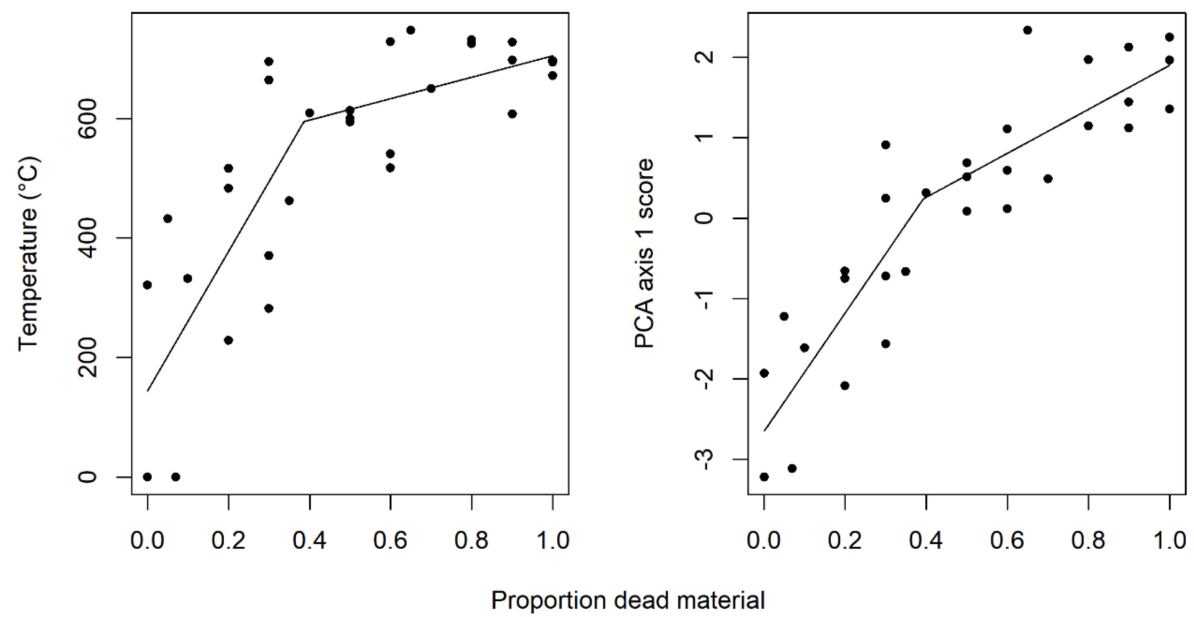

Figure 4. Piecewise regression models for combustibility (temperature $\left({ }^{\circ} \mathrm{C}\right)$ ) and overall flammability (PCA axis 1 scores). The breakpoint in both models is at a dead material proportion of $39 \%$. 


\section{Discussion}

It has been well documented that high retention of dead material leads to elevated flammability [9,11,12]; however, the nature of this relationship has rarely been explored. Our experiments have quantified this association in gorse. The different components of flammability (combustibility, consumability and sustainability) had varying responses to dead material. While all components increased in relation to the proportion of dead material, the response of maximum temperature (combustibility) was shown to saturate at 39\% dead material.

Maximum temperature was best modelled by an asymptotic non-linear regression. An increase in dead material initially corresponded to an increase in maximum temperature; however, the response saturated at approximately 39\% dead material. A similar saturation effect was demonstrated in Adenostoma fasciculatum by Schwilk [8] who found that the experimental removal of dead branches lowered local fire temperatures, but the addition of dead material did not significantly increase temperatures. Pausas et al. [10] reported that standing dead biomass in Ulex parviflorus could reach $65 \%$ in mature populations. Therefore, the proposed saturation point is within the natural range for Ulex stands, albeit approximately only half of the upper limit.

Proportion of burnt biomass increased in a linear fashion relative to increases in dead material. This relationship can be attributed to the high consumability of dead fuel and the facilitation of live fuel burning. Dead material is more readily consumed than live material due to its low water content [7]. In accordance with this, the dead portion of $U$. europaeus was entirely consumed during each burn of this study. The consumption of dead fuel also facilitates live fuel consumption because the heat that is generated drives excess water out of living tissue [1]. Such a facilitation effect would have been amplified as the proportion of dead material increased.

Flame duration was also shown to be linearly correlated with the proportion of dead material. A key characteristic affecting the sustainability of plant combustion is moisture content [25]. This can explain the observed relationship because, as was demonstrated in our samples, dead material has significantly lower water content than live material [1]. As the proportion of dead material increased, the overall water content of the sample would have decreased and this is likely to have enhanced flame sustainability. Longer flame duration may also be due to a correlated increase in sample consumability; it takes longer to burn proportionately more material.

Overall flammability was observed to have a non-linear relationship with dead material with the slope of the line decreasing after the break point of $39 \%$. This is important because it predicts that increases in dead material up to $39 \%$ will correspond to dramatic increases in plant flammability, while increases beyond the $39 \%$ threshold will have less impact. These results support the suggestion of [9] that in order to best mitigate the fire hazard associated with Ulex spp., stands should be kept at a young stage where there is a relatively low proportion of dead material.

While our laboratory-based approach does not replicate field conditions, we feel that placing shoots horizontally on the grill does a reasonable job of representing the architecture of gorse plants found in the field. Some shoots on gorse are held horizontally and, crucially, the dead material is largely found underneath the live material (Figure 2). We aimed to represent this alignment on our device as best we could. However, as Schwilk [8] showed with his elegant experiment, the architecture of plants in the field plays a key role in influencing fire behaviour and can override other factors like fuel loads. Consequently, our findings should be tested using field experiments. Such field tests should help overcome some of the limitations in our approach, such as different levels of aeration likely to have been present in the fuel mix (Figure 2).

The aim of this study was to quantify the nature of the relationship between dead fuel accumulation and flammability in $U$. europaeus. We showed that three components of flammability increased in response to higher proportions of dead material. Flame duration (sustainability) and proportion of burnt biomass (consumability) did so in a linear manner, whereas maximum temperature (combustibility) was asymptotic. These findings offer clarification of plant flammability associated 
with this well-known phenomenon and provide further suggestions as to methods of fire hazard management in gorse shrublands.

Author Contributions: Conceptualization, T.J.C.; Data curation, J.M.D.; Formal analysis, J.M.D., H.L.B., A.L. and T.J.C.; Investigation, J.M.D., T.J.C. and H.L.B.; Methodology, T.J.C.; Supervision, T.J.C. and H.L.B.; Writing original draft, J.M.D.; Writing - review \& editing, T.J.C., H.L.B. and A.L.

Funding: This research was funded by a Lincoln University Early Career Award and a Lincoln University Research Fund grant to TJC.

Acknowledgments: We thank Phil Holland for assistance with data collection, Conrad O'Dell for allowing us to collect gorse from his property and the staff at the Field Service Centre at Lincoln University for access to drying ovens and balances.

Conflicts of Interest: The authors declare no conflict of interest. The funders had no role in the design of the study; in the collection, analyses, or interpretation of data; in the writing of the manuscript, or in the decision to publish the results.

\section{References}

1. Bond, W.J; Van Wilgen, B.W. Fire and Plants; Population and Community Biology Series; Chapman \& Hall: London, UK; CSIR: Stellenbosch, South Africa, 1996.

2. Whelan, R.J. The Ecology of Fire. In Cambridge Studies in Ecology, 1st ed.; Cambridge University Press: Cambridge, UK, 1995.

3. Anderson, H.E. Forest fuel ignitibility. Fire Technol. 1970, 6, 312-319. [CrossRef]

4. White, R.H.; Zipperer, W.C. Testing and classification of individual plants for fire behaviour: Plant selection for the wildland-urban interface. Int. J. Wildl. Fire 2010, 19, 213-227. [CrossRef]

5. Wragg, P.D.; Mielke, T.; Tilman, D. Forbs, grasses, and grassland fire behaviour. J. Ecol. 2018, 106, $1983-2001$. [CrossRef]

6. Baeza, M.J.; Raventós, J.; Escarré, A.; Vallejo, V.R. Fire risk and vegetation structural dynamics in Mediterranean shrubland. Plant Ecol. 2006, 187, 189-201. [CrossRef]

7. Cowan, P.D.; Ackerly, D.D. Post-fire regeneration strategies and flammability traits of California chaparral shrubs. Int. J. Wildl. Fire 2010, 19, 984-989. [CrossRef]

8. Schwilk, D.W. Flammability is a niche construction trait: Canopy architecture affects fire intensity. Am. Nat. 2003, 162, 725-733. [CrossRef]

9. Baeza, M.J.; De Lu1s, M.; Raventós, J.; Escarré, A. Factors influencing fire behaviour in shrublands of different stand ages and the implications for using prescribed burning to reduce wildfire risk. J. Environ. Manag. 2002, 65, 199-208. [CrossRef]

10. Pausas, J.G.; Alessio, G.A.; Moreira, B.; Corcobado, G. Fires enhance flammability in Ulex parviflorus. New Phytol. 2012, 193, 18-23. [CrossRef]

11. MacCarter, L.E.; Gaynor, D.L. Gorse: A subject for biological control in New Zealand. N. Z. J. Exp. Agric. 1980, 8, 321-330. [CrossRef]

12. Papió, C.; Trabaud, L. Structural characteristics of fuel components of five Mediterranean shrubs. For. Ecol. Manag. 1990, 35, 249-259. [CrossRef]

13. Moreira, B.; Castellanos, M.C.; Pausas, J.G. Genetic component of flammability variation in a Mediterranean shrub. Mol. Ecol. 2014, 23, 1213-1223. [CrossRef] [PubMed]

14. Rolston, M.P.; Talbot, J. Soil temperatures and regrowth of gorse burnt after treatment with herbicides. N. Z. J. Exp. Agric. 1980, 8, 55-61. [CrossRef]

15. Fernandes, P.M.; Cruz, M.G. Plant flammability experiments offer limited insight into vegetation-fire dynamics interactions. New Phytol. 2012, 194, 606-609. [CrossRef]

16. Lee, W.G.; Allen, R.B.; Johnson, P.N. Succession and dynamics of gorse (Ulex europaeus L.) communities in the Dunedin ecological district south island, New Zealand. N. Z. J. Bot. 1986, 24, 279-292. [CrossRef]

17. Jaureguiberry, P.; Bertone, G.; Diaz, S. Device for the standard measurement of shoot flammability in the field. Austral Ecol. 2011, 36, 821-829. [CrossRef]

18. Wyse, S.V.; Perry, G.L.; O'Connell, D.M.; Holland, P.S.; Wright, M.J.; Hosted, C.L.; Whitelock, S.L.; Geary, I.J.; Maurin, K.J.; Curran, T.J. A quantitative assessment of shoot flammability for 60 tree and shrub species supports rankings based on expert opinion. Int. J. Wildl. Fire 2016, 25, 466-477. [CrossRef] 
19. Wyse, S.V.; Perry, G.L.; Curran, T.J. Shoot-level flammability of species mixtures is driven by the most flammable species: Implications for vegetation-fire feedbacks favouring invasive species. Ecosystems 2018, 21, 886-900. [CrossRef]

20. Burger, N.; Bond, W.J. Flammability traits of Cape shrubland species with different post-fire recruitment strategies. S. Afr. J. Bot. 2015, 101, 40-48. [CrossRef]

21. Padullés Cubino, J.; Buckley, H.L.; Day, N.J.; Pieper, R.; Curran, T.J. Community-level flammability declines over 25 years of plant invasion in grasslands. J. Ecol. 2018, 106, 1582-1594. [CrossRef]

22. Day, R.W.; Quinn, G.P. Comparisons of treatments after an analysis of variance in ecology. Ecol. Monogr. 1989, 59, 433-463. [CrossRef]

23. Anderson, D.R. Model Based Inference in the Life Sciences: A Primer on Evidence, 1st ed.; Springer-Verlag: New York, NY, USA, 2007.

24. Toms, J.D.; Lesperance, M.L. Piecewise regression: A tool for identifying ecological thresholds. Ecology 2003, 84, 2034-2041. [CrossRef]

25. Madrigal, J.; Marino, E.; Guijarro, M.; Hernando, C.; Díez, C. Evaluation of the flammability of gorse (Ulex europaeus L.) managed by prescribed burning. Ann. For. Sci. 2012, 69, 387-397. [CrossRef]

(C) 2019 by the authors. Licensee MDPI, Basel, Switzerland. This article is an open access article distributed under the terms and conditions of the Creative Commons Attribution (CC BY) license (http:/ / creativecommons.org/licenses/by/4.0/). 